\title{
Modelling and simulation of operation \& maintenance strategy for offshore wind farms based on multi-agent system
}

\author{
M'hammed SAHNOUN · David BAUDRY · \\ Navonil MUSTAFEE · Anne LOUIS · Philip Andi \\ SMART · Phill GODSIFF • Belahcene MAZARI
}

Received: date / Accepted: date

\begin{abstract}
Maintenance of offshore wind turbines is a complex and costly undertaking which acts as a barrier to the development of this source of energy. Factors such as the size of the turbines, the size of the wind farms, their distance from the coast, meteorological conditions, etc. make it difficult for the stakeholders to select the optimal maintenance strategy. With the objective of reducing costs and duration of such operations it is important that new maintenance techniques are investigated. In this paper we propose a hybrid model of maintenance that is based on multi-agent systems, which allows for the modelling of systems with dynamic interactions between multiple parts. A multi-criteria decision algorithm has been
\end{abstract}

M'hammed SAHNOUN

IRISE/CESI, 1, Rue G. Marconi, Mont-Saint-Aignan, France

Tel.: +33-235-128-674

Mob: +33-673-642-966

E-mail: msahnoun@cesi.fr

David BAUDRY

LUSINE/CESI, 1, Rue G. Marconi, Mont-Saint-Aignan, France.

E-mail: dbaudry@cesi.fr

Navonil MUSTAFEE

University of Exeter ISR, Exeter EX4 4ST, UK

E-mail: n.mustafee@exeter.ac.uk

Anne LOUIS

IRISE Laboratory - CESI Rouen, France

E-mail: alouis@cesi.fr

Philip Andi SMART

University of Exeter ISR, Exeter EX4 4ST, UK

E-mail: p.a.smart@exeter.ac.uk

Phil GODSIFF

University of Exeter ISR, Exeter EX4 4ST, UK

E-mail: phil.godsiff@exeter.ac.uk

Belahcene MAZARI

IRISE Laboratory - CESI Rouen, France

E-mail: bmazari@cesi.fr 
developed to allow analysis and selection of different maintenance strategies. A cost model that includes maintenance action cost, energy loss and installation of monitoring system cost has been presented. For the purposes of this research we have developed a simulator using NetLogo software and have provided experimental results. The results show that employing the proposed hybrid maintenance strategy could increase wind farm productivity and reduce maintenance cost.

Keywords Offshore wind turbine $\cdot$ Renewable energy $\cdot$ Maintenance $\cdot$ Failure modes · Multi-agent systems $\cdot$ Simulation

\section{Introduction}

An offshore wind farm (OWF) is defined as a collection of wind turbines and associated equipment to generate electricity from wind power. The principal factors influencing the choice of a site are its distance from coastal facilities, water depth, and wind quality [29]. This source of energy has the potential to become the biggest source of energy in the future $[37,22]$. Europe is the world leader in developing such farms from the Nordic countries, such as Sweden and Denmark, through to Holland [25]. Several countries are interested in this kind of energy, such as France, which expects to have operational farms developed by 2018 [17]. The most challenging obstacle to the ongoing development of this source of energy is the high cost of installation, operation and maintenance compared with other sources of energy [25]. The maintenance of offshore wind turbines is difficult and expensive especially when site weather conditions are hostile [11]. As a result, it is estimated that the cost of maintaining offshore wind turbines makes up between; $25 \%$ to $40 \%$ of the total $\mathrm{kWh}$ cost of electricity, compared with $10 \%$ to $15 \%$ of onshore terrestrial sites. This high cost is extremely sensitive to the type of maintenance strategy adopted: for example preventive maintenance costs between 0.003 and $0.006(€ / \mathrm{kWh})$ while corrective maintenance cost is between 0.005 and $0.01(€ / \mathrm{kWh})$ [41]. Reducing maintenance costs is a key step in establishing the future of offshore wind farms.

Several researchers have studied the optimisation of maintenance strategies for offshore wind farms [23, 20, 3]. For example [39] propose a strategy based on a permanent base (using a hotel boat with a permanent repair team) within the farm allowing for rapid interventions in the case of a breakdown. [41] suggests locating several large cranes within the farm to reduce maintenance time for large heavy pieces of equipment such as gearboxes. They have shown that having multiple large cranes of 50 MT costing $k € 150$ is less expensive in the long term than traditional repair voyages as this configuration will enable important maintenance in short weather windows.

[5] proposes an analytical model able to compute the performance of a maintenance support for offshore wind farms with alternative transportation means. The same team has proposed to use reliability centred maintenance to wind turbines [18]. Nilsson et al [34] present the approach used for operation and maintenance at two companies, Swedish Vattenfall and Danish Elsam, and propose the improvement of maintenance strategy using Condition Monitoring Systems. [8] and [33] have put forward a strategy based on the risks and costs of avoiding corrective maintenance. A review of extant literature on Operation and Maintenance (O\&M) optimisation is presented in [11].

Modelling and simulating of offshore wind farms is an essential task in establishing an optimum maintenance strategy. The involvement of several actors in the operation of the system makes the modelling task both complex and difficult [43]. Several research teams 
are currently developing simulations covering one or several parts of the system. [36] set out a restricted model using Petri-nets, but suggest several possible uses and developments of their model. Byon et al [11] have created a discrete event simulation model based on Discrete Event System Specification (DEVS) including principal component of the turbine. Their results show the advantages of a condition based strategy over a scheduled or systemic strategy (their study focussed on the gearbox). Van de Pieterman et al [39] have developed a model, based on historical data, to calculate maintenance costs by examining the transport system and have established an optimal solution based on the type of breakdown. Although the aforementioned studies have provided important insight into the maintenance of wind farms, they have often ignored factors such as the weather conditions, distance from coast and the difficulty of access. As our study focuses specifically on offshore we have considered these geographical factors in our analysis of alternative maintenance strategies.

Using distributed architectures, specifically Multi-Agent System (MAS), is an interesting choice for modelling such problems [40]. MAS has been used for systems' modelling and simulation in many application domains (manufacturing, transport and logistics, supply chains, healthcare); it has also been used for control and modelling of offshore energy systems such as petroleum platform [49,9] modelling maintenance activities [53].Conventional methods of modelling and simulation are unable to ensure the required level of safety and performance of such systems [31]. Through this modelling approach a researcher is able to model each part (agent) in the system independently, and subsequently add the interactions and relationships between the different parts of the system [15]. This paper puts forward a MAS model for offshore wind turbine maintenance taking into account a variety of potential failure modes in the turbine and also geographical conditions that may affect maintenance operations. A new maintenance strategy is proposed which increases the uptime and reduces cost; the strategy is tested through simulation.

Following this introduction section, the remainder of the paper is organised as follows. In section 2 we set out the types and causes of the most significant failures of the parts of the wind turbine in order to define the interaction between the turbine and its environment; in section 3 we present the multi-agent model with a description of the agents and their interactions and the developed cost model; section 4 describes the simulation based on our model and a comparison between our hybrid maintenance strategy and other forms of strategies (e.g., systemic and condition-based strategies). We conclude the paper with a more general discussion and considerations for further research.

\section{Failures of offshore wind turbines}

One significant advantage of offshore wind turbines is the ability of the wind farm operators to install much larger turbines (e.g. blade length in excess of $90 \mathrm{~m}$ ) enabling power production of $6 \mathrm{MW}$ and above [29]. However, larger turbines and extreme weather conditions increases the difficulty of O\&M, even though the cost per kW.h reduces with the size of the turbine [7]. A study of a Danish wind farm [24] has shown that $60 \%$ of breakdowns concern the electrical system, the gearbox, the directional control system, the generator, and the hydraulic system (Figure 1). In order to define an efficient maintenance plan, it is therefore important to analyse the types of failure and their underlying causes. This will enable the identification of specific interactions between the turbines and their environment, and would consequently result in better system representation using multi-agent modelling. In the reminder of this section we examine the types and causes of breakdown for crucial parts of the wind turbine as shown on the Figure1. 


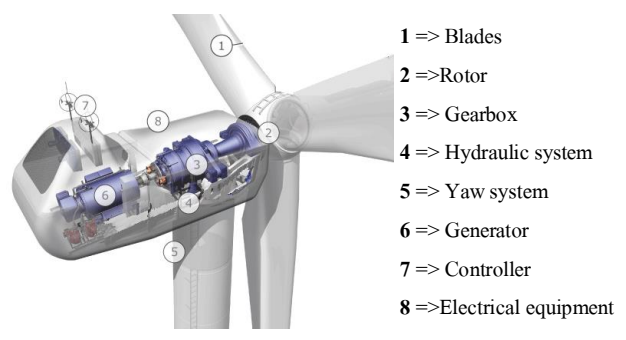

Fig. 1 Crucial subsystem of an offshore wind turbine, based on [16]

\subsection{Failure of the electrical system}

This part includes all the electrical components and the wires connecting them (Figure 1-8). The principal types of failure in the electrical system are failures in the armatures, short circuits and damage to the electrical components, transformers and wiring breaks [4]. The most significant causes of these breakdowns are short-circuit caused by power surges, poor installation, and technical faults in electronic components (e.g. resistors and capacitors).

\subsection{Failure of the yaw system}

This system controls the orientation of the nacelle (turbine housing) in order to follow the wind direction (Figure 1-5). In general, one encounters problems with cracking of yaw drive shafts, failures of the rotational bearings and fixings, and fractures of the gears [4]. These failures are due to the formation of ice on the nacelle, high vibration during periods of strong winds outside safe operating conditions, and failures linked to breakdown in the motor unit [47].

\subsection{Failure of the gearbox}

The gearbox (Figure 1-3) is a crucial component of the turbine, but it also represents the weakest part in the turbine experiencing the most frequent breakdowns [45]; replacement is complicated and time consuming (approximately 5 days [41]). The principal failure modes are associated with rotational issues and broken gear teeth [32]. These are frequently the results of particulate contamination, frequent stopping and starting of the turbine, and operating outside safe wind speeds [4].

\subsection{Failures associated with the hydraulic system}

Hydraulic components (Figure 1-4) are used in multiple high pressure locations within the turbine such as the directional control, the gearbox, braking systems, and so on. The issues surrounding fluid leakages from hydraulic components are a well known source of failure. They are essentially due to frequent changes in temperature, corrosion, vibration, bad design and poor component quality. Improper installation of hydraulic systems is responsible for $60 \%$ of failures [35]. 


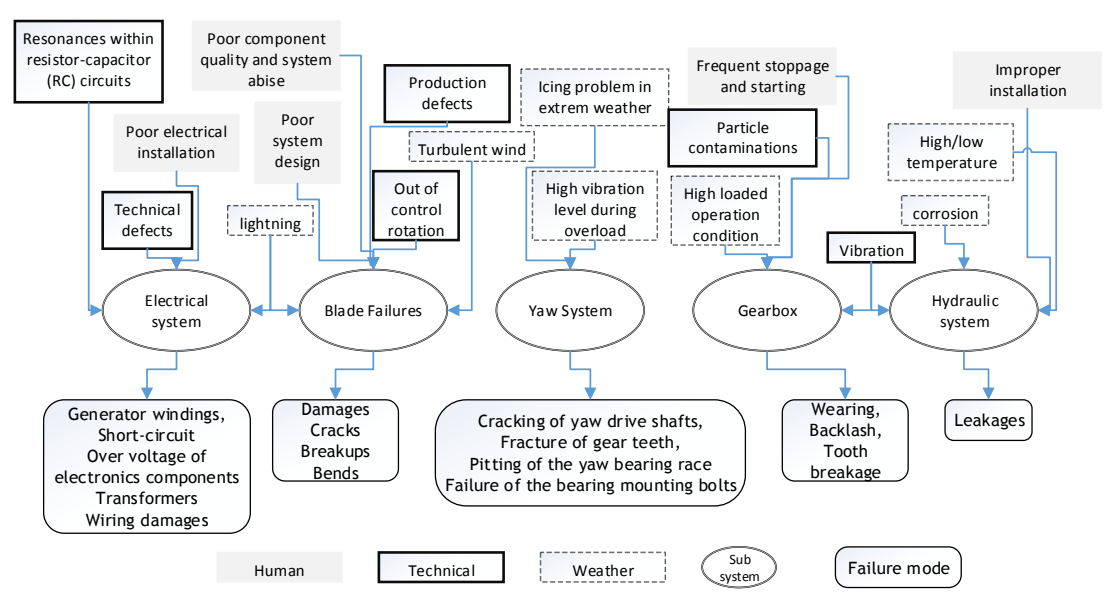

Fig. 2 Principal cause of turbine failure

\subsection{Turbine blade failures}

The turbine blades are aerodynamically designed to convert wind energy to mechanical energy (and subsequently electrical) (Figure 1-1). We can generalise and group under blade failures as breakages, splits, and vibration damage. Principal causes of blade failure are wind turbulence, uncontrolled rotation and operation, electrical storms and manufacturing faults [6].

\subsection{Classification of failure causes}

With regards to classifying the causes of failure of the different components within the turbine, we have used the following three broad areas: the weather; human operating errors (human), and product quality or technical effects (technical) as represented in Figure 2. Developing a maintenance strategy has to take into account all these elements. The model which we describe below takes into account the effects of the weather on the turbines and the different failure types resulting from the underlying faults of construction or installation.

\section{Multi-agent system modelling}

The maintenance of an offshore wind farm is a complex task because of the geographical spread of the O\&M activity. Also, it is subject to constraints associated with the weather, and the availability of qualified human resources, spare parts, appropriate boats and cranes. The success of a maintenance task depends on the intervention of several parts within the system. The decomposition of the system into several interacting parts and considering each part in isolation is an effective approach which can reduce complexity of the modelling task. Using a multi-agent-system architecture is an interesting and useful method for modelling and simulating such a system. 


\subsection{Global model}

We have divided the system into five interconnected parts, each part consisting of one or more autonomous agents, (depicted in Figure 3). We have considered the following five types of agents:

- Turbine agent

- Maintenance agent

- Resources agent

- Monitoring agent

- Weather agent

Inter-agent interactions are numbered from 1 to 8 (see Figure 3).

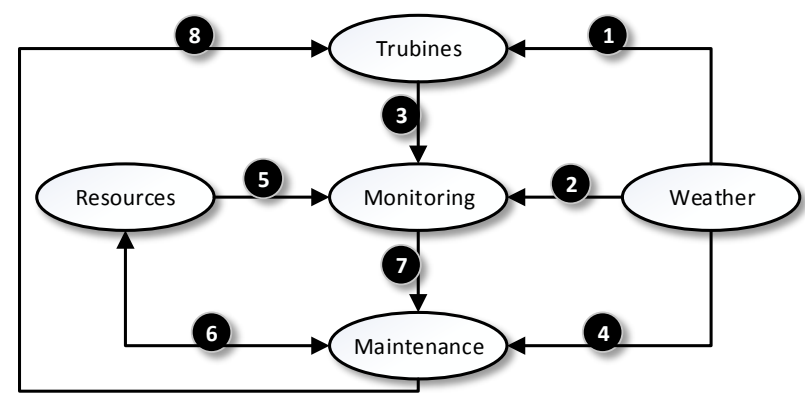

Fig. 3 Multi-agent model: agents and their interactions

In the following section of the paper we describe the behaviour and composition of the agents and provide justification of their respective roles.

\subsection{Agent "Turbine"}

Each turbine is represented by an autonomous agent able to interact with its environment composed of other agents such as: "Maintenance", "Weather" and "Monitoring" (see Figure 3).

Every agent "Turbine" consists of variables, which represents the state of the turbine, its Equipment Health Factor $(E H F)$ and the energy that it produces. Figure 4 presents the parameters specific to the "Turbine" agent and their relationships. Each agent "Turbine" follows two rules, namely, turbine degradation and turbine production, which are influenced by several internal variables (e.g., the quality of components, the size of the turbine, and its age) and external variables that are generated by the other agents:

- Weather conditions determine the energy produced as a result of wind speed and direction (Figure 3, interaction 1). It also affects turbine degradation, where weather conditions are one of the principal failure cause of the wind turbines [46] (see Section 2).

- The agent "Maintenance" affects directly the production and the degradation level of the turbine. Indeed, the turbine is stopped during the maintenance task. However, after a maintenance task, the $E H F$ is increased to its maximum value. (Figure 3, interaction 8). 
- The relation between the monitoring and the turbine (Figure 3, interaction 3) consists in the information provided by the turbine about its state, its $E H F$ and the energy produced.

- Other turbines influence the degradation and the production of each agent turbine where they share the limited maintenance resources, which influences the maintenance activity of the turbine. If there is a remanufacturing policy in the management of the OWF, spare parts recovered from other turbines are refurbished and used for future maintenance tasks. This will change the availability, the quality of spare parts and then the degradation manner and production of the turbine [13]. Energy produced by each turbine is influenced also by the wake effect generated by other turbines [38],[2]. There exists three principal wake effect models for the wind, Jensen model [54, 26], Ainslie model [1] and G.C Larsen model [30]. All these models consider the variation of the wind speed or the turbulence, but none of the wake effect models have made the relation between turbine degradation and the wake loss effect. In addition the wake loss effect on maintenance strategy is not clearly defined in literature [28]. In our study we are using the same configuration of the OWF and the same weather conditions, hence we haven't considered this effect in our developed model.

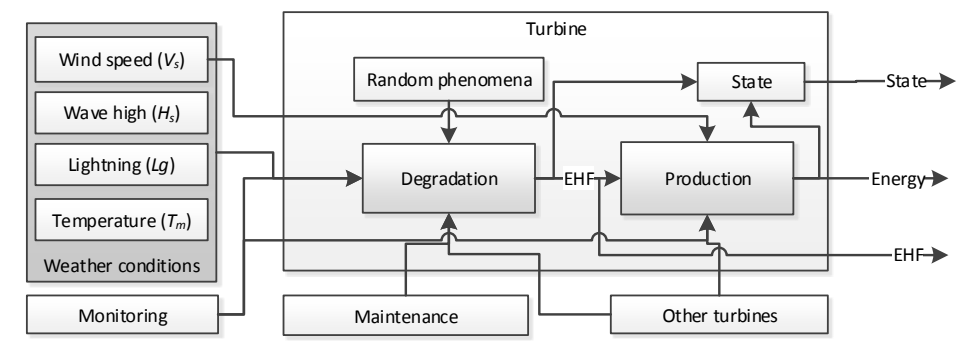

Fig. 4 The composition and behaviour of the agent "Turbine"

\subsubsection{Power production}

The energy produced by a turbine depends on the wind speed, the state of the turbine and its capacity of production. We consider several technical specifications associated with the production of electricity according to the speed of the wind $V_{s}$, principally:

- $V_{c i n}$ the cut-in wind speed representing the lowest wind speed at which electricity can be generated.

- $V_{\text {cout }}$ the cut-out wind speed which is the maximum allowable for safe operation. The turbine is shut down if the wind speed exceeds this value.

- $V_{r}$ the rated wind speed which is the minimum wind speed at which each individual turbine can produce its maximum energy.

The power generated by each turbine follows a classical model of the power curve of the wind turbines [27], [44] as presented in Figure 5. According to [27] the power generated by a turbine with a wind speed of $V_{s}$ is calculated by the following equation: 


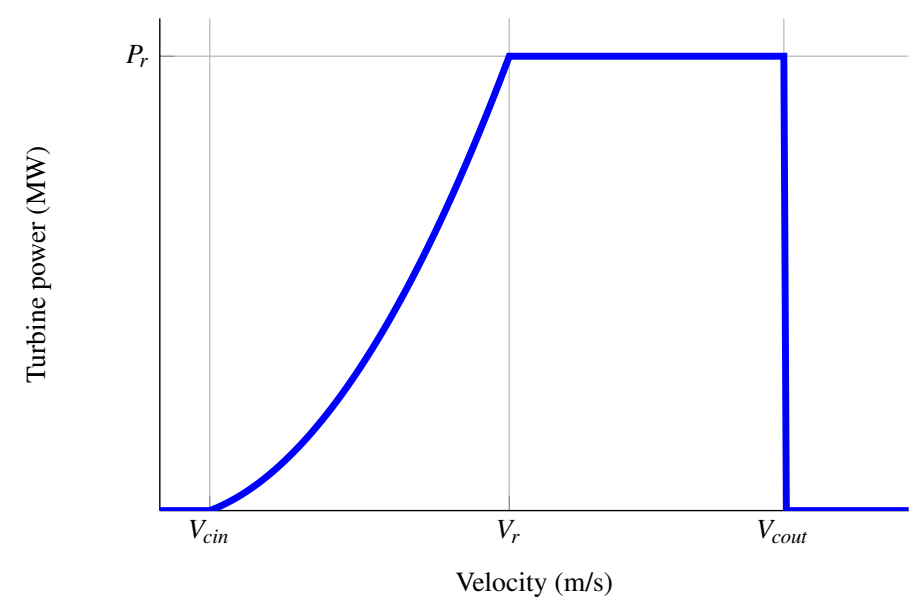

Fig. 5 The turbine power curve with maximum production $p_{r}=6 \mathrm{MW}$

$$
P= \begin{cases}0 & \text { if } 0 \leq V_{s}<V_{\text {cin }} \\ P_{r} \cdot\left(a+b \cdot V_{s}+c \cdot V_{s}^{2}\right) & \text { if } V_{\text {cin }} \leq V_{s}<V_{r} \\ P_{r} & \text { if } V_{r} \leq V_{s}<V_{\text {cout }} \\ 0 & \text { if } V_{\text {cout }} \leq V_{s}\end{cases}
$$

Where $P_{r}$ is the rated power output of the wind turbine. The parameters $a, b$ and $c$ in equation (1) are obtained from the following equations:

$$
\begin{aligned}
& a=\frac{1}{\left(V_{\text {cin }}-V_{r}\right)^{2}}\left[V_{\text {cin }}\left(V_{\text {cin }}+V r\right)-4 V_{\text {cin }} V_{r}\left(\frac{V_{\text {cin }}+V_{r}}{2 V_{r}}\right)^{3}\right] \\
& b=\frac{1}{\left(V_{\text {cin }}-V_{r}\right)^{2}}\left[4\left(V_{\text {cin }}+V r\right)\left(\frac{V_{c i n}+V_{r}}{2 V_{r}}\right)^{3}-\left(3 V_{\text {cin }}+V_{r}\right)\right] \\
& c=\frac{1}{\left(V_{\text {cin }}-V_{r}\right)^{2}}\left[2-4\left(\frac{V_{\text {cin }}+V_{r}}{2 V_{r}}\right)^{3}\right]
\end{aligned}
$$

The wind speed is measured by meteorological stations often situated at ground or sea level. This measured speed is not the same as the speed at the height of the nacelle and this difference depends on the nacelle height, the height of the meteorological station, and the type of terrain separating the station and the turbine [9]. The wind speed at the turbine height is given by the following relation $[21,55]$ :

$$
V_{s}=V_{0} \times\left(\frac{h}{h_{0}}\right)^{\alpha}
$$

Where:

- $h$ : The nacelle height

- $h_{0}$ : The measurement point height

- $V_{s}$ : The wind speed anemometer height $h$ (nacelle) at the turbine location

- $V_{0}$ : The wind speed at hub height $h_{0}$

- $\alpha$ : The wind speed power law coefficient, this value mainly depends on the local geographical terrain. 


\subsubsection{Degradation and state change}

The degradation of turbines is caused by several phenomena and affecting several part of the turbine (refer to section 2). From a reliability point of view, the discussed parts of the turbine are connected in series, which allows the use of global indicators of degradation affected by all the cause named in the previous section (sub-section 2.6)[48]. We suggest several performance indicators such as, the Equipment Health Factor $(E H F)$ and the time since the last inspection or maintenance event to estimate the degradation level of the the turbine and to define its state.

The $E H F$ of each turbine decreases in time due to asset depreciation and weather effects. It varies between 10 (the turbine is new or "as good as new") and 0 (the turbine has failed). Further, the $E H F$ model considers random degradation due to the improper installation, poor quality of the turbine components or indeed rare-events such as lightning strike. It varies also by the maintenance task executed on the turbine. The $E H F$ of a given turbine $i$ at the instant $k+1$ is expressed as follows:

$$
E H F_{i}(k+1)= \begin{cases}0 & \text { if } f_{i}(k+1)=1 \\ E H F_{\text {max }} & \text { if } M_{i}(k+1)=1 \\ \gamma_{i}(k) \times\left(E H F_{i}(k)-\operatorname{deg}_{t d}(k+1)-\operatorname{deg}_{t r}(k+1)\right) & \text { Otherwise }\end{cases}
$$

Where:

- $f_{i}(k+1)$ : is the probability that a failure which stops the turbine $i$, occurs at the instant $k+1$. It follows an exponential probability distribution with an average of 5 years which represents the MTBF ( Mean time Between Failures) of the turbine. This value represents an average of the most important unexpected failures causing the turbine to immediately stop functioning, e.g., due to the breakdown of the gearbox, turbine blades, generator or the hydraulic system [42]. The computation is based on the data available in [9].

- $E H F_{\text {max }}$ : is the value of the $E H F$ when a turbine is new. We consider an "as good as new" approach of maintenance $[12,10,11,19]$, i.e., subsequent to a maintenance operation the turbine becomes as good as new at least for its principal function. In our case the $E H F_{\max }=10$

- $M_{i}(k+1)$ : is a variable equal to 1 when a maintenance task is performed on turbine $i(0$ otherwise).

- $\operatorname{deg}_{t d}(k+1)$ : is the time-dependent degradation per simulation step (a day in our case). It depends on the last value of $E H F(k)$, where degradation rate is proportional to the wind turbine degradation i.e $\left(E H F_{\max }-E H F(k)\right)$. Therefore, the deterministic temporal degradation is defined as follows:

$$
\operatorname{deg}_{t d}(k+1)=\phi \times\left(E H F_{\text {max }}-E H F(k)\right)
$$

Where: $\phi$ is defined empirically to ensure an $E H F$ value equal to 0 after 10 years without any external phenomenon.

- $\operatorname{deg}_{t r}$ : is the random environment-dependent degradation per simulation step (one day). It follows a uniform distribution with parameters $a=0$ and $b=\theta \times \operatorname{deg}_{t d}$. $\theta$ represents the maximum ratio between deterministic and random degradation. In this study, $\theta=10$.

- $\gamma_{i}(k)$ : represents the coefficient of the effect of weather conditions on the turbine degradation, it is expressed as follows:

$$
\gamma_{i}(k)=\gamma_{i}^{T m}(k) \times \gamma_{i}^{v}(k) \times \gamma_{i}^{l g}(k)
$$


Where:

$$
\begin{aligned}
& \gamma_{i}^{T m}(k)= \begin{cases}\gamma^{T m} \text { if temperature degrades the turbine } i \\
1 & \text { otherwise } \\
\gamma^{v} \text { if wind speed degrades the turbine } i \\
1 \text { otherwise } \\
\gamma_{i}^{v}(k)\end{cases} \\
& \gamma_{i}^{l g}(k)= \begin{cases}\text { if lightning degrades the turbine } i \\
1 & \text { otherwise }\end{cases}
\end{aligned}
$$

Values of $\gamma^{T m}, \gamma^{\nu}$ and $\gamma^{l g}$ are included in the interval [0,1[ and denote respectively the rate of the effect of temperature, wind speed and lightning on the turbine. For example if the turbine $i$ with an $E H F=E H F_{\text {Before wind effect }}$ is subject to a strong wind, its $E H F$ After wind effect can be defined as follows:

$$
\begin{aligned}
E H F_{\text {After wind effect }} & =\gamma_{i}^{T m}(k) \times \gamma_{i}^{v}(k) \times \gamma_{i}^{l g}(k) \times E H F_{\text {Before wind effect }} \\
& =1 \times \gamma^{v} \times 1 \times E H F_{\text {Before wind effect }}
\end{aligned}
$$

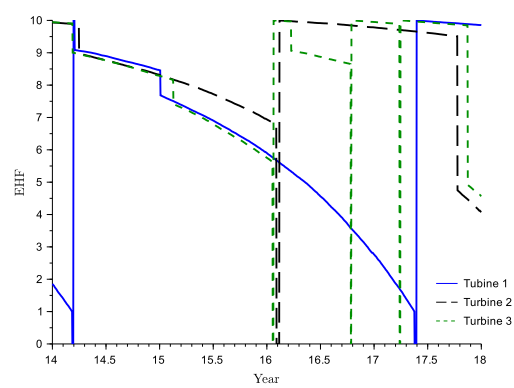

Fig. 6 Example of EHF variation for three different turbines

We consider that weather conditions can degrade the turbine if they exceed the nominal values, i.e., $V_{s}>V_{r} ; T_{m}<0^{\circ}$ or $T_{m}>40^{\circ}$. In case of a lightening strike it degrades one or more turbines. Figure 6 illustrates the variation in $E H F$ for three different turbines. $E H F$ decreases with time and also as a result of random changes due to the effect of weather conditions or internal failures. After each maintenance task the $E H F$ is restored to 10 (max).

Each turbine can be in one of a finite number of situations (states) regarding its degradation level the maintenance tasks and its functioning. Table 1 summarises the different situations of the turbine:

- Situation $1(8 \leq E H F \leq 10)$ : the operation mode is "Normal" and the turbine can either be in operation or in stop condition (the latter happens when maintenance task is being carried out or due to the high wind speeds). Note that if the wind speed is above $25 \mathrm{~m} / \mathrm{s}$ the turbine must be stopped in order to avoid a potential situation wherein the wind may damage the turbine.

- Situation $2(4 \leq E H F<8)$ : the operation mode is "Degraded" and the turbine can be either in operation or in the stop condition. In this state the probability of the turbine requiring a maintenance operation is higher compared to situation 1. 
Table 1 State of the turbine regarding the $E H F$, the maintenance and the operation mode

\begin{tabular}{llll}
\hline EHF & Operation mode & Operation & Maintenance \\
\hline 8 to 10 & Normal & On & Off \\
& & Off & On \\
& & Off \\
4 to 8 & \multirow{2}{*}{ Degraded } & On & Off \\
& & Off & On \\
\multirow{2}{*}{1 to 4} & \multirow{2}{*}{ Alert } & On & Off \\
& & Off & On \\
$\leq 1$ & \multirow{2}{*}{ Failed } & Off & Off \\
& & & On \\
\hline
\end{tabular}

- Situation $3(1 \leq E H F<4)$ : the operation mode is "Alert" and the turbine can be either in operation or in stop condition. In this case the probability of the turbine requiring a maintenance task is higher when compared to the earlier two situations (with states "Normal" and "Degraded" respectively).

- Situation $4(E H F \leq 1)$ : the operation mode is "Failed" and the turbine is in stop condition. In this case the turbine needs a corrective maintenance action.

\subsection{Agent "Weather"}

Variations in meteorological conditions are represented by the agent "weather". This is characterised by wind speed $V_{s}$, wave height $H_{s}$, lightning, and visibility. These parameters are provided by real historical data or by the appropriate statistical distribution (Weibulle for $V_{s}$ and Rayleigh for $H_{s}$ [9]) with adapted parameters that varies according to the seasons. Weather condition limits, which restrict the maintenance task execution, are defined by a wind speed $V_{s}=8 \mathrm{~m} / \mathrm{s}$ and a wave high $H_{s}=1.5 \mathrm{~m}$.

The behaviour of the agent "Weather" is defined by an "update" function able to generate characteristic of the weather, and a function "degrade" able to represent the effect of the weather on the turbine performance. This agent is affects turbine degradation (Figure 3, interaction 1), the monitoring decision (Figure 3, interaction 2) and the maintenance task.

\subsection{Agents "Resource"}

We have defined several types of resource agents, which can either be material resources or human resources.

- The materials agents are: boats, spare parts and cranes

- The human agents are: engineers and technicians

The difference between an engineer and a technician is based on the cost of each one and the type of tasks that it performs.

Each agent "Resource" has two states: "busy" during the maintenance task and "available" otherwise. The use of each material agent generates a cost and a carbon footprint, whereas the use of a human agent generates a cost only. In this study, we have not considered the carbon footprint and assume that the inventory of spare parts is unlimited. 
3.5 Agents "Maintenance"

Maintenance tasks are represented by different types of agents. Each agent is characterised by its own type, cost and requirements in terms of resources and operating conditions (weather window, breakdown type). We have considered three types of maintenance as shown in Figure 7:

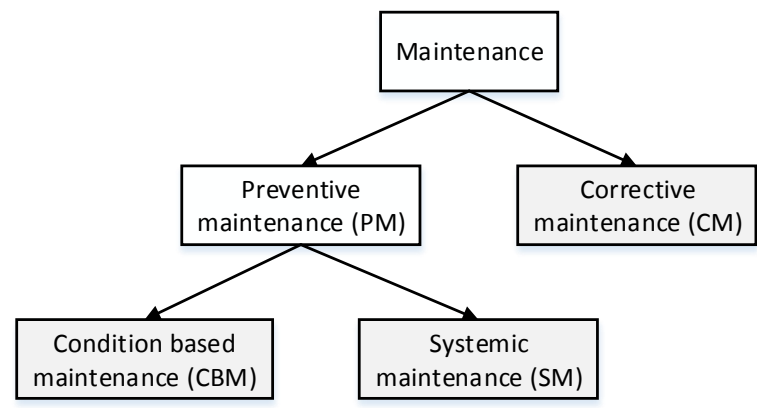

Fig. 7 Classification of maintenance types

- Corrective maintenance (CM): This type of maintenance is performed to repair a significant failure when the turbine is stopped. This is a very costly strategy that requires significant material (e.g., subcontractors, medium or big boat, heavy cranes) and possible delays between two and six days to perform the necessary tasks. Hence, this strategy is not recommended. In our model, this strategy is not used unless the turbine has suffered a breakdown.

- Systemic maintenance ( $S M$ ): It is one of the two kinds of preventive maintenance (see Figure 7). It is carried out according to a defined schedule and when weather conditions permit. If we have a regular degradation model, this strategy is the most effective. Often, lubricants and other components, such as gaskets and hoses, have an expected life of less than a year and are replaced. In addition, regular inspections are carried out during the SM task. The SM takes between one and two days and requires on average one engineer and two technicians.

- Condition Based Maintenance (CBM): It is the second variant of preventive maintenance (see Figure 7). It is driven by information about the performance of the turbine provided by the monitoring system. The decision of performing a CBM can be multi or monoobjective [51]. This strategy is generally used in conjunction with a fault tree to diagnose root causes. It is recommended to take the opportunity of CBM tasks to perform tasks planned for systemic maintenance.

The different types of maintenance agent require careful management of the inter-relationships between facts and potential intervention dates to increase the efficiency of maintenance. We have assumed that the action of maintenance restores the turbine to its "Normal" operation mode, and restores all operational indicators to their required states before the breakdown. The behaviour of the maintenance agents can be described by the following functions: 
- Resource demand: This combines the necessary material and human resources together in order to carry out the specified task (Figure 3, interaction 6). The agent maintenance ask resources to be busy when the weather conditions are safe.

- Repair: This function starts the repair action on the turbine (Figure 3, interaction 8), during which the turbine is stopped and is set in maintenance mode.

- Return resources: Once the maintenance task is completed, this function returns the used resources (Figure 3, interaction 6), allows the turbine to restart and provoke the self-destruct of the agent "Maintenance".

\subsection{Agent "Monitoring"}

This agent is in charge of planning the maintenance tasks and prioritising between the various turbines that require maintenance. It controls the state of the other agents (Figure 3, interaction 3) and ensures that each turbine receives appropriate maintenance.

The choice of the turbine to maintain is based on the following criteria: (1) its date of the next preventive systemic maintenance (SM), (2) its degradation level ,(3) its operation mode and its state, (4) the weather conditions (Figure 3, interaction 2) and the resource availability (Figure 3, interaction 5).

The choice of maintenance type is dependent on the selection cause of the turbine, i.e the maintenance type is systemic (SM) when the turbine is chosen on a time basis, and condition-based $(\mathrm{CBM})$ when the turbine is chosen on degradation $(E H F)$ basis. If the weather window does not allow the performance of long maintenance task, the monitoring can choose another maintenance type more shorter. Furthermore, when a turbine fails, a corrective maintenance action (CM) is chosen and accomplished. This agent can order several maintenance tasks for several turbine at the same time (Figure 3, interaction 7). Figure 8 summarises the global functioning of the "Monitoring" agent.

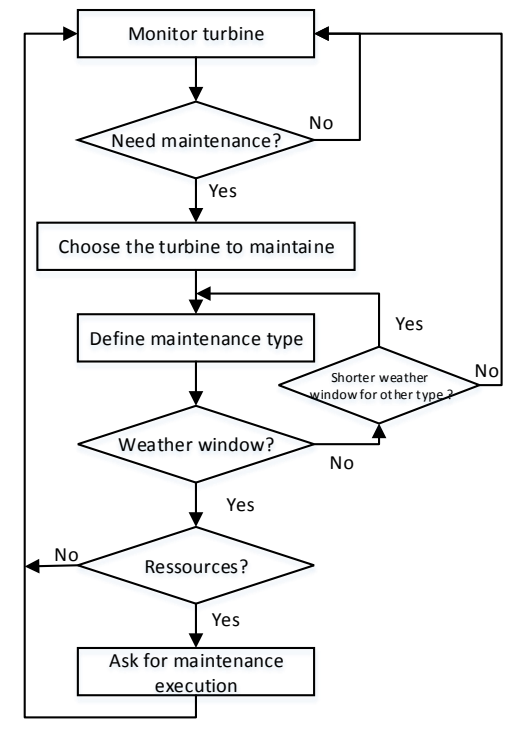

Fig. 8 Flowchart showing the logic followed by the "Monitoring" agent 
The Agent "Monitoring" follows two rules "monitor" - where it collects information from the other agents - and "select" - where it chooses the turbine to maintain and the type of maintenance to perform.

\subsection{Cost model}

The maintenance cost is an important criterion in the decision making of maintenance strategy. It depends on several parameters such as the failure types, the maintenance types, the maintenance duration, the weather conditions, and the cost of the maintenance facilities [34].

The adopted maintenance-cost-model is a parameter affected by several agents, for instance, the "Maintenance" agent generates a cost at every maintenance action; this cost is depending of the maintenance type chosen and the resources that are used. When the turbine is stopped or functioning in a degraded mode, the produced energy is less than the nominal state; this loss of production is also considered as a cost due to the maintenance strategy. We consider that the corrective maintenance task is more expensive than a preventive maintenance task; according to [41] we consider that the cost of a corrective maintenance is equivalent to tow systemic maintenance tasks. When the condition-based maintenance is used the cost of the installation of monitoring system is add to the global cost of maintenance and it depending of the $E H F$ of the turbine.

The total cost $(C T)$ of maintenance over a given period of time (simulation period) can be expressed as follows:

$$
\begin{aligned}
C T & =I s_{c b m} \times C_{i n i t}+C_{s m}+C_{c b m}+C_{c m}+C_{d o w n}+C_{d e g} \\
& =I s_{c b m} \times C_{i n i t}+\sum_{k=1}^{N} C T(k)
\end{aligned}
$$

where:

- $I s_{c b m}$ : a binary variable equal to 1 if a monitoring system for the condition based maintenance is installed and 0 otherwise.

- $C_{\text {init }}$ : the cost of installation of the monitoring system for the condition based maintenance.

- $C_{s m}, C_{c b m}$ and $C_{c m}$ : are respectively the cost of the systemic, condition-based and corrective maintenance. They include the cost of spare parts, and the cost of human resources and material resources.

$-C_{d o w n}$ : the cost of energy loss due to turbine maintenance or turbine failure.

$-C_{d e g}$ : the cost of energy loss due to the functioning in degraded mode.

- $C T(k)$ is the total cost at simulation step $k$; it can be expressed by the following relation:

$$
\begin{aligned}
C T(k)=\sum_{t r=1}^{t r=N T}\left(C_{s m}(t r, k) \cdot X_{s m}(t r, k)\right. & +C_{c b m}(t r, k) \cdot X_{c b m}(t r, k)+P_{e}(t r, k) \cdot(\operatorname{Deg}(t r, k) \\
& \left.+\operatorname{Down}(t r, k))+C_{c m}(t r, k) \cdot X_{c m}(t r, k)\right)
\end{aligned}
$$

where:

- NT is the number of turbines in the offshore wind farm.

- $C_{s m}(t r, k), C_{c b m}(t r, k)$ and $C_{c m}(t r, k)$ are respectively the daly cost of the systemic, condition based and corrective maintenance of the turbine $t r$ at the instant $k$

- $X_{s m}(t r, k), X_{c b m}(t r, k)$ and $X_{c m}(t r, k)$ are binary variables defined as follows: 
$\{1$ if the corresponding type of maintenance is performed on the turbine $t r$ at the instant $k$ 0 otherwise

- $P_{e}(t r, k)$ is the profit generated by the turbine $t r$ in a normal state during a day $k$.

- Deg $(t r, k)$ the cost of lost energy due to the degradation of the turbine $t r$ at the instant $k$. It can be expressed as follows:

$$
\operatorname{Deg}(t r, k)=\frac{E H F_{\max }-E H F(t r, k)}{E H F_{\max }}
$$

The cost due to the degradation of a turbine $t r$ at the instant $k$ can be expressed as follows:

$$
C_{d e g}(t r, k)=P_{e}(t r, k) \times \operatorname{Deg}(t r, k)
$$

- Down $(t r, k)$ is a binary variable defining the state a the turbine $t r$, where:

$$
\operatorname{Down}(t r, k)=\left\{\begin{array}{l}
1 \text { if the turbine } t r \text { is failed at the instant } k \\
0 \text { otherwise }
\end{array}\right.
$$

The cost of energy loss due to the turbine stopping because of a maintenance or failure of a turbine $t r$ at the instant $k$ can be expressed as follows:

$$
C_{d o w n}(t r, k)=P_{e}(t r, k) \times \operatorname{Down}(t r, k)
$$

\subsection{Interactions between agents}

Assume an OWF which comprises of NT turbines, affected by the agent "Weather" impacting on both production and degradation of the turbines. Each "Turbine" agent changes its state under the effect of the "Maintenance" and "Weather" agents. The "Monitoring" agent assesses all the turbines states and reports on those which are broken or which need to be maintained. It selects the turbine to maintain and the maintenance type to perform and assesses whether the agent "Maintenance" is available; i.e., it checks if the agent "Maintenance has sufficient resources and appropriate weather conditions to carry out the required tasks. The agent "Maintenance" requests the necessary resources and starts repairing the turbine during the duration defined by the "Monitoring" agent. When the maintenance operation is complete, resources are returned before the self-destruction of the agent "Maintenance". The resources agents are then set available and wait for a new call by other "Maintenance" agents. These interactions are summarised in Table 2.

Figure 9 shows the relations between the agents and the decisions made and the actions taken by the agents.

\section{Experiments and discussions}

This section describes the developed simulator based on the model described above, the scenario used to compare different type of maintenance and discuss results of the conduced simulations in term of cost and electricity production of each maintenance strategy. 
Table 2 Decisions taken by the system

\begin{tabular}{llll}
\hline Decisions & $\begin{array}{l}\text { Concerned } \\
\text { agents }\end{array}$ & Conditions & Actions/Consequences \\
\hline $\begin{array}{l}\text { Maintenance } \\
\text { scheduling }\end{array}$ & Monitoring & $\begin{array}{l}\text { - Maintenance duration } \\
\text { - Availability of required re- } \\
\text { sources } \\
\text { - Weather conditions and } \\
\text { weather window }\end{array}$ & $\begin{array}{l}\text { - Determination of the date of the } \\
\text { next maintenance task and the } \\
\text { turbine to maintain }\end{array}$ \\
\hline $\begin{array}{l}\text { Maintenance } \\
\text { action }\end{array}$ & Maintenance & $\begin{array}{l}\text { - Degradation level } \\
\text { - Required resources }\end{array}$ & - Turbine repair \\
\hline Degradation & - Turbine & $\begin{array}{l}\text { - Weather conditions } \\
\text { - Degradation level } \\
\text { - Turbine state }\end{array}$ & $\begin{array}{l}\text { - Degradation of turbines and } \\
\text { their components }\end{array}$ \\
\hline Production & - Turbine & $\begin{array}{l}\text { - Weather conditions } \\
\text { - Degradation level } \\
\text { - Turbine state }\end{array}$ & - Production of electricity \\
\hline
\end{tabular}

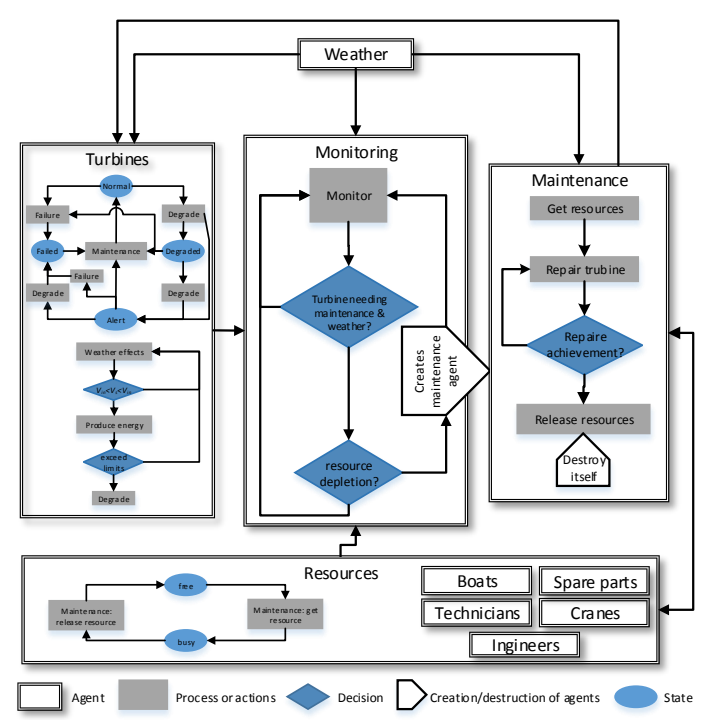

Fig. 9 Global functioning diagram

\subsection{Simulator}

We have used the software NetLogo 5.1.0 to develop a simulator based on the model defined in the previous section. NetLogo is a multi-agent programmable modelling environment, particularly well suited for modelling complex systems evolving over time [52]. 
The objective of the developed simulator is to compare different maintenance strategies, based on the generated power and maintenance cost over the life cycle of a turbine. The developed simulator's interface (Figure 10) is composed from three kind of views:

1. The representation of the offshore wind farm, composed of wind turbines, and the management teams such as engineers, technicians and their tools.

2. Representations of monitoring indicators (weather, parameters of turbines and evolution of maintenance tasks,...) that allow the decision making.

3. A control interface composed of a set of buttons, sliders and switches that allows the user to change the parameters of the simulation such as the number of turbines, the maintenance type and the maintenance team size.

A dedicated 2D view is used to visualise the animations of the turbines and the positions of maintenance. This interface facilitates the understanding of the actions and behaviour of each agent. The animated interface of the simulator is composed of the following:

- The wind farm composed from turbines. each turbine is animated when it produce energy. The state of each turbine is represented by a different colour: green for normal functioning, yellow for alert, orange for critical, and red for broken. When maintenance is being carried out, the colour of the turbine changes to black.

- The maintenance task is represented visually by a wrench placed on behind the turbine which is in maintenance. The wrench disappears when the maintenance operation is completed..

- Resources specific to the engineers, technicians, boats and cranes are represented by different chaps with an indication of the number of available agent of each type.

In order to control easily the simulator and perform several scenarios, we have add several slider and switches to control the parameters of the the simulation. The control interface of the simulator (Figure 10) allows to change the following parameter settings:

- Size of the offshore wind farm $(N T)$.

- Type of used maintenance (systemic, condition based and corrective).

- Parameters of preventive maintenance ( delay of systemic maintenance and threshold of condition based maintenance).

- Size of maintenance team, namely the number of : engineer, technicians, boats and cranes.

- Time horizon of the simulation (from 1 to 30 years).

- Parameters related to the display and animation.

Using the visual interface of the simulation, several performance indicators including power production, the situation of the weather conditions, the evolution of the state of turbines, etc. can be observed at run-time. The simulator's interface contains some plots and displays of real-time evolution of the following performance indicators:

- Produced energy of the wind farm.

- Number of tasks belonging to each selected type of maintenance.

- Total cost $T C$ of the maintenance.

- Weather conditions: temperature $T_{m}$, wind speed $V_{s}$, waves height $H_{s}$ and lightening $L_{g}$.

- Equipment Heal Factor $E H F$ of turbines (a sample of 3 turbines). 


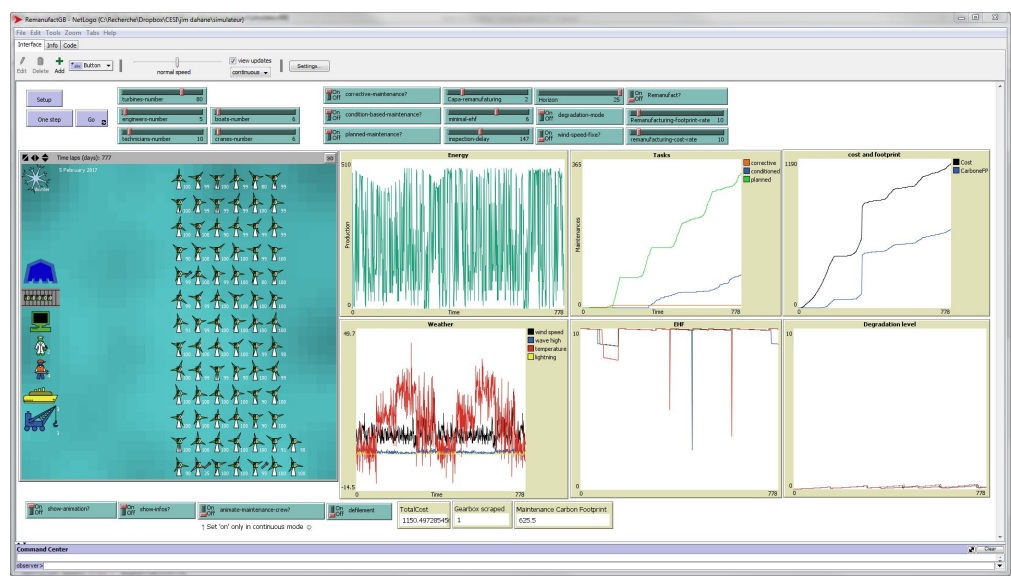

Fig. 10 Screenshot of the simulator interface designed using Netlogo software

\subsection{Simulation}

We have assumed an OWF composed of 80 wind turbine with a nominal maximum power output of $P_{r}=6 M W$; start up wind speed $V_{\text {cin }}=4 \mathrm{~m} / \mathrm{s}$; rated wind speed $V_{r}=14 \mathrm{~m} / \mathrm{s}$; and safety stop maximum wind speed $V_{\text {cout }}=25 \mathrm{~m} / \mathrm{s}$ [29]. The maintenance of this OWF is made by 5 independent mobile maintenance units, each of them is composed of: 1 maintenance engineer; 2 maintenance technicians; 1 boat; and 1 crane. The duration of the maintenance task is depending of the nature of failure and the type of maintenance. Indeed, the duration of a corrective maintenance varies from 1 to 3 open days, while the duration of preventive maintenance (systemic or condition based) 1 to 2 days.

Concerning the weather conditions, we used historical data of wind speed $V_{s}$ obtained from Le Havre airport, situated on the English Channel (La Manche) coast. We have assumed that this wind speed is not very different from the wind speed measured in the position of the OWF. For wave height $H_{s}$, we have used Rayleighs' distribution, with a parameter $\sigma$ that varies according to the season [50]. As the NetLogo software does not have such a function, we have used the following relation [14] to generate wave height using the uniform distribution available on NetLogo:

$$
H_{s}=\sigma \times \sqrt{-\log U}
$$

Where :

$U$ is a uniform random variable taking values between 0 and 1.

The lightning is generated following a uniform distribution regarding the season. To identify the effect of the particular maintenance strategy on OWF performances, we have run and compared several scenarios of maintenance strategy. Because of the considerable necessary time to plan and perform maintenance tasks and because the obtained historical data of wind speed are composed of a daily average, we have considered a step simulation of 1 day.

We have examined 3 types of maintenance strategies to compare the effect of each strategy on overall power production and maintenance cost. The strategies adopted were: 
- Systemic Maintenance Strategy (SMS): this strategy is based on systemic maintenance actions performed every 6 months combined with corrective maintenance action performed in case of breakdown. After a maintenance task, the date of the systemic maintenance is re-computed.

- Condition Based Maintenance Strategy (CBMS) : this strategy is based on CBM maintenance actions required when the $E H F$ of the turbine is less than the limit value of 6 combined with corrective maintenance actions performed in case of breakdown.

- Hybrid Strategy (combining conditional, systemic and corrective: HS): based on the monitoring agent selecting which type of maintenance task to perform based on the turbine chosen for maintenance. If the turbine chosen has a low health state a conditional task is chosen, if selected because it wasn't maintained since over than 6 months the systemic maintenance task is performed, and if selected following a breakdown a corrective maintenance task is chosen.

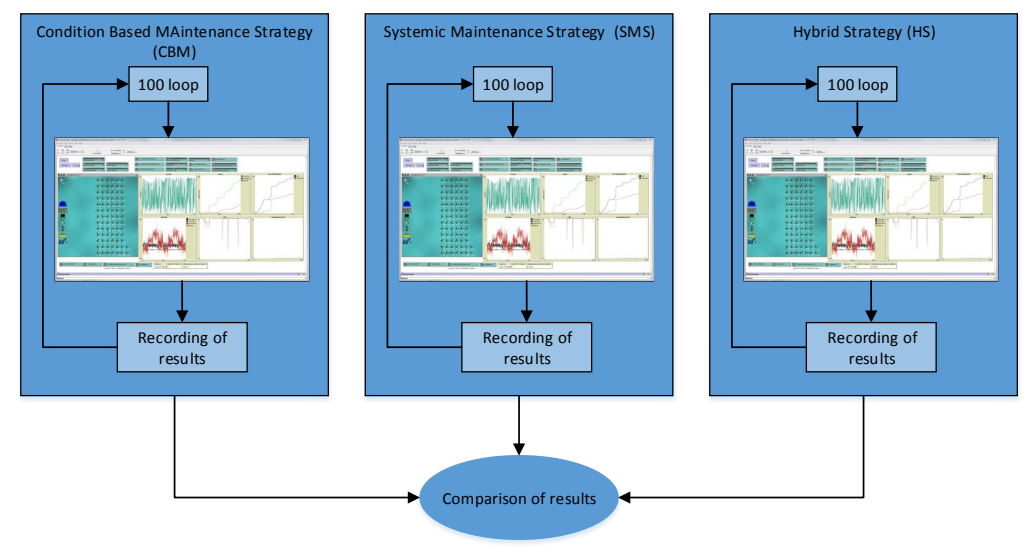

Fig. 11 Simulation plan

Because of the random nature of several parameters of the model (maintenance duration, weather conditions ...), all presented results are the averages of 100 simulations for each strategy as represented on the Figure 11.

Figure 12 represents the level of energy produced over a period of 25 years of simulation for the three adopted strategies and the reference case where the turbine are never failed. It shows that the maintenance strategy and the weather conditions have a significant influence on the production of energy. The daily production on Figure 12(b) indicates that the production varies according to the season of the year. The comparison of values over a period of 25 years demonstrates that a hybrid strategy which we have suggested produces the best results compared with other strategies (CBM strategy and SM strategy) with a production average of $97 \%$ of the ideal case. Notice that the ideal case ( without failure ) produce $52 \%$ of the potential output of the farm. The two other strategies produce $95 \%$ and $90 \%$ of the case without failures for CBM and SM strategy respectively.

Figure 13 presents the yearly (Figure 13(a)) and daily (Figure 13(b)) evolution of cost over the period of simulation ( 25 year) for the three strategies. The cost is computed according to the model presented in the section 3.7. The obtained results show the efficiency of the hybrid strategy in term of cost, where the slope of of the hybrid strategy cost curve (cf. 


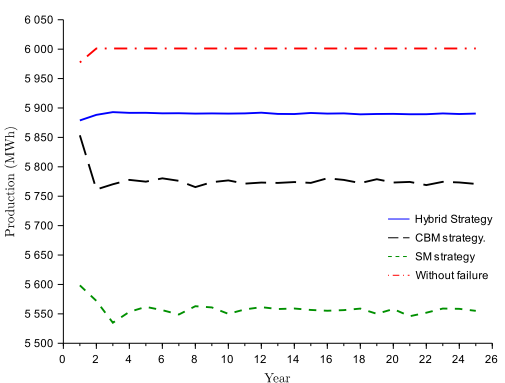

(a) Yearly average

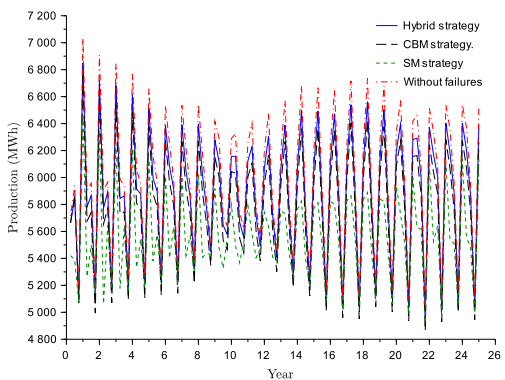

(b) Daily average

Fig. 12 Electricity production variation over 25 years

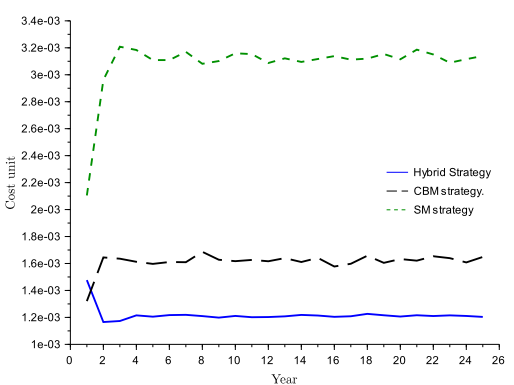

(a) Yearly cost average per MWh

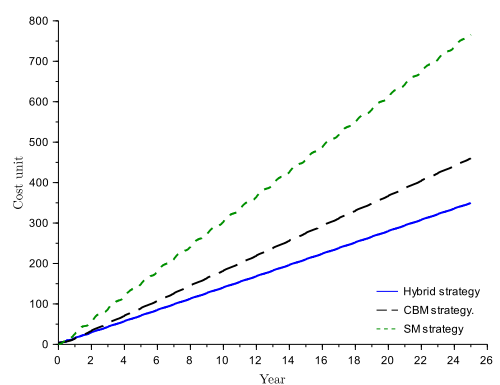

(b) Cumulative maintenance cost

Fig. 13 Cost variation over 25 years

Figure 13(b)) is lower than the slops of the two other strategies. We observe also that the SM strategy is more costly than the CBM strategy (cf. Figure 13). The degradation model of the turbine influences the cost of the maintenance strategy. In a previous study [42], we found that the CBM strategy is more costly than the SM strategy with the use of a linear degradation model of turbines. This can indicates that the strategy of maintenance is highly influenced by the quality of the turbine.

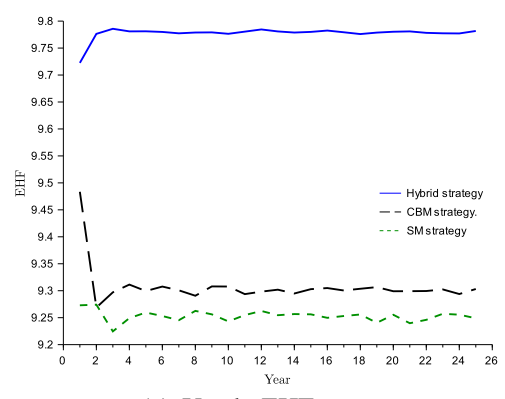

(a) Yearly EHF average

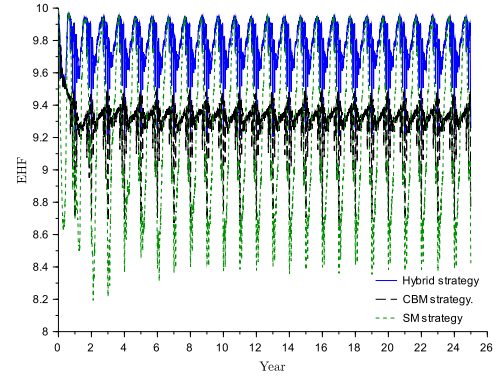

(b) Daily EHF variation

Fig. 14 EHF variation over 25 year 
Table 3 Comparison of maintenance strategy in term of cost, EHF, production and number of maintenance tasks over 25 year

\begin{tabular}{llll}
\hline & CBM Strategy & SM Strategy & Hybrid Strategy \\
\hline Number of CBM task & 1039 & 0 & 986 \\
Number of SM task & 0 & 4162 & 3781 \\
Number of CM task & 1020 & 459 & 312 \\
Total task number & 2059 & 4621 & 5079 \\
Cost [Cost unit] & 11046 & 18378 & 8389 \\
mean EHF & 9.3 & 9.25 & 9.8 \\
Cumulative production [GWh] & 52713 & 50714 & 53747 \\
\hline
\end{tabular}

In addition, the hybrid strategy improves the average of the OWF equipment health factor more than the two other strategies as shown on the Figure 14. Concerning the EHF, the CBM strategy gives also better results than the SM strategy (cf. Figure 14(a)).

Table 3 summarizes the performances of each maintenance strategy, in terms of cost, cumulative production and the number of performed maintenance tasks per maintenance type.

A condition based maintenance strategy requires the least number of maintenance task with 2059 interventions but it is more costly than the hybrid maintenance strategy which need 5079 intervention during the 25 year of operation. Even if the SM strategy presents a big number of maintenance actions it remains the most costly strategy. This can be explained by the level of production, where the hybrid strategy produce the most important quantity of energy because it keeps the turbines in good health ( mean EHF =9.8), whereas, the SM strategy is the most costly because of its loss in production as shown on Figure 12. The CBM strategy has a lot of Corrective tasks (1020) which is very costly and undesired. This can be improved by playing on the launching threshold of CBM tasks. The hybrid strategy demonstrates an interesting performance for further examination; with the most important number of interventions compared with the other strategies, but it presents the least costly strategy thanks to its high level of production (more than 97\%). We notice also that the type of maintenance task carried out most often in the hybrid strategy is systemic maintenance with approximately two-thirds of the maintenance tasks carried out. This regular maintenance of turbine explains the finding that the turbines are in good health $(\mathrm{EHF}=9.8)$ and that they do not deteriorate as often as under condition-based maintenance.

Using the multi agent based simulator, we have demonstrated the effectiveness of our proposed strategy. Our hybrid strategy produces noteworthy results for offshore turbine maintenance, which present well known maintenance difficulties and constraints. The hybrid strategy allows the choice of a compromise between the production of energy, the cost of maintenance, weather conditions and the health of the turbine, enabled by the choice of which turbine to maintain and what type of task to perform.

\section{Conclusion and Future Work}

Offshore wind energy is increasingly becoming an important point of discussion in both scientific and political discourse. This paper has examined the challenges of implementing an optimal maintenance strategy for offshore wind farms. We present a literature review to identify the cause of turbine failure. Based on this we define interactions between the different actuator in the offshore wind farms and propose a multi-agent based model of the 
system functioning. Next, a simulator which was developed using the NetLogo program is described. After that, a cost maintenance model taking into account several cost types is then proposed. The last part of this paper discussed the results of the comparison between three maintenance strategies (systemic (SMS) condition-based (CBMS) and a hybrid strategy (HS)). The results show that, in comparison to the other strategies, the hybrid approach HS allows the generation of more power and at lower costs, this in spite of the large number of maintenance tasks that are required for the hybrid strategy. Reviewing these results we are able to conclude that the hybrid strategy is a viable maintenance approach which should be taken into consideration by the stakeholders while planning maintenance activities.

We now discuss the opportunities for future work. The decision algorithm, which chooses which turbine to maintain, and the type of task, is based on a simple comparison of health states of all the turbines and the dates of systemic maintenance. Improving this algorithm will be the basis of our next steps in the short term. The optimisation of parameters of the systemic and condition-based maintenance will improve the maintenance strategy by reducing the number of maintenance tasks and increasing their efficiency. Each turbine is represented currently by an independent agent and we intend to develop our model in order to treat the turbine as a group of agents (e.g. gearbox, electric system, ...) in its own right. The interaction between turbines in term of wake loss effects and information share will be considered. Several other developments are possible in both the model and the simulator to further optimise planning and performing maintenance tasks covering other sorts of maintenance (for example pro-active maintenance), using other maintenance approaches (for example as good as old), and reducing the simulation time period to 30 minutes rather than one day.

\section{ACKNOWLEDGEMENT}

Acknowledgement is made to European Union for the support of this research through the European Program INTERREG IVA France-Channel-UK by funding project entitled MER Innovate.

\section{References}

1. Ainslie JF (1988) Calculating the flowfield in the wake of wind turbines. Journal of Wind Engineering and Industrial Aerodynamics 27(1):213-224

2. Ammara I, Leclerc C, Masson C (2002) A viscous three-dimensional differential/actuator-disk method for the aerodynamic analysis of wind farms. Journal of Solar Energy Engineering 124(4):345-356

3. Astariz S, Perez-Collazo C, Abanades J, Iglesias G (2015) Co-located wind-wave farm synergies (operation \& maintenance): A case study. Energy Conversion and Management 91:63-75

4. Babu JR, Jithesh S (2008) Breakdown risks in wind energy turbines. Pravartak, the journal of Insurance and risk Management from National Insurance Academy, Pun 3(3)

5. Besnard F, Fischer K, Tjernberg LB (2013) A model for the optimization of the maintenance support organization for offshore wind farms. Sustainable Energy, IEEE Transactions on 4(2):443-450 
6. Bill Chun Piu Lau, Eden Wai Man Ma MP (2012) Review of offshore wind turbine failures and fault prognostic methods. Proceedings of the IEEE 2012 Prognostics and System Health Management Conference (PHM-2012 Beijing) pp 1-5, DOI 10.1109/ PHM.2012.6228954

7. Braam H, Verbruggen TW (2000) R \& D NEEDS FOR O \& M OF WIND TURBINES

8. Brennan F (2013) Risk based maintenance for offshore wind structures. Procedia CIRP 11:296-300

9. Burton T, Jenkins N, Sharpe D, Bossanyi E (2011) Wind energy handbook. John Wiley \& Sons

10. Byon E, Ntaimo L, Ding Y (2010) Optimal maintenance strategies for wind turbine systems under stochastic weather conditions. Reliability, IEEE Transactions on 59(2):393404

11. Byon E, Pérez E, Ding Y, Ntaimo L (2011) Simulation of wind farm operations and maintenance using discrete event system specification. Simulation 87(12):1093-1117

12. Cunha P, Duarte JC, Alting L (2004) Development of a productive service module based on a life cycle perspective of maintenance issues. CIRP Annals-Manufacturing Technology 53(1):13-16

13. Dahane M, Sahnoun M, Bettayeb B, Baudry D, Boudhar H (2015) Impact of spare parts remanufacturing on the operation and maintenance performance of offshore wind turbines: a multi-agent approach. Journal of Intelligent Manufacturing pp 119, DOI 10.1007/s10845-015-1154-1, URL http://dx.doi.org/10.1007/ s10845-015-1154-1

14. Del M (2010) precis de simulation. INIRIA

15. Dimeas AL, Hatziargyriou ND (2005) Operation of a multiagent system for microgrid control. IEEE TRANSACTIONS ON POWER SYSTEMS PWRS 20(3):1447

16. Energy C (2014) The basic components of a turbine. URL http://www . coriolis-energy.com/wind_energy/wind_technology.html

17. Fécamp EDPD (2013) Biln carbone du parc olien en mer au large de fécamp

18. Fischer K, Besnard F, Bertling L (2012) Reliability-centered maintenance for wind turbines based on statistical analysis and practical experience. Energy Conversion, IEEE Transactions on 27(1):184-195

19. Gundegjerde C, Halvorsen IB, Halvorsen-Weare EE, Hvattum LM, Nonås LM (2015) A stochastic fleet size and mix model for maintenance operations at offshore wind farms. Transportation Research Part C: Emerging Technologies 52:74-92

20. Haddad G, Sandborn P, Pecht M (2014) Using maintenance options to maximize the benefits of prognostics for wind farms. Wind Energy 17(5):775-791

21. Hau E, Von Renouard H (2013) Wind turbines: fundamentals, technologies, application, economics. Springer

22. Henderson AR, Morgan C, Smith HC, Barthelmie RJ, Boesmans B (2003) Offshore wind energy in europea review of the state-of-the-art. Wind energy 6(1):35-52

23. Herbert GJ, Iniyan S, Amutha D (2014) A review of technical issues on the development of wind farms. Renewable and Sustainable Energy Reviews 32:619-641

24. Hyers R, McGowan J, Sullivan K, Manwell J, Syrett B (2006) Condition monitoring and prognosis of utility scale wind turbines. Energy Materials 1(3):187-203

25. Ivan Pineda SA, Moccia J, Wilkes J (2014) Wind in power 2013 (February):1-12

26. Jensen NO (1983) A note on wind generator interaction

27. Karki R, Patel J (2009) Reliability assessment of a wind power delivery system. Proceedings of the Institution of Mechanical Engineers, Part O: Journal of Risk and Reliability 223(1):51-58, DOI 10.1243/1748006XJRR218 
28. Kim H, Singh C, Sprintson A (2012) Simulation and estimation of reliability in a wind farm considering the wake effect. Sustainable Energy, IEEE Transactions on 3(2):274282

29. Kooijman H, Lindenburg C, Winkelaar D, van der Hooft E (2003) Dowec 6 mw predesign. Energy Research Center of the Netherlands (ECN)

30. Larsen GC (1988) A simple wake calculation procedure

31. Liyanage JP (2008) Integrated e-operations-e-maintenance: Applications in north sea offshore assets. In: Complex System Maintenance Handbook, Springer, pp 585-609

32. Lu B (2012) A Review of Recent Advances in Wind Turbine Condition Monitoring and Fault Diagnosis

33. Nielsen JJ, Sørensen JD (2011) On risk-based operation and maintenance of offshore wind turbine components. Reliability Engineering \& System Safety 96(1):218-229

34. Nilsson J, Bertling L (2007) Maintenance management of wind power systems using condition monitoring systems mdash;life cycle cost analysis for two case studies. Energy Conversion, IEEE Transactions on 22(1):223-229, DOI 10.1109/TEC.2006. 889623

35. Palanci A (2011) Leak-free hydraulic fittings prevent vibration failure. Windpower Engineering for Parker Hannifin, WTWH Media, Inc, 11th April

36. Pérez M, García E, Morant F, Correcher A, Quiles E (2010) Optimal maintenance system for offshore wind turbines. In: International Conference on Renewable Energies and Power Quality (ICREPQ10). Granada (Spain), 23th to 25th March

37. Perveen R, Kishor N, Mohanty SR (2014) Off-shore wind farm development: Present status and challenges. Renewable and Sustainable Energy Reviews 29:780-792

38. Petković D, Ab Hamid SH, Ćojbašić Ž, Pavlović NT (2014) Adapting project management method and anfis strategy for variables selection and analyzing wind turbine wake effect. Natural Hazards 74(2):463-475

39. Van de Pieterman R, Braam H, Obdam T, Rademakers L, van der Zee T (2011) Optimisation of maintenance strategies for offshore wind farms. In: The Offshore 2011 Conference

40. Radakovič M, Obitko M, Mařík V (2012) Dynamic explicitly specified behaviors in distributed agent-based industrial solutions. Journal of Intelligent Manufacturing 23(6):2601-2621

41. Rademakers L, Braam H, Zaaijer MB, Energy SW (2003) Assessment and optimisation of operation and maintenance of offshore wind turbines

42. Sahnoun M, Baudry D, Louis A, Mazari B (2014) Modelisation d'un plan de maintenance basee sur les systemes multi-agents pour leseoliennes offshore

43. Sahnoun M, Bettayeb B, Bassetto SJ, Tollenaere M (2014) Simulation-based optimization of sampling plans to reduce inspections while mastering the risk exposure in semiconductor manufacturing. Journal of Intelligent Manufacturing pp 115, DOI 10.1007/s10845-014-0956-x, URL http://dx.doi.org/10.1007/ s10845-014-0956-x

44. Sahnoun M, Godsiff P, Baudry D, Louis A, Mazari B (2014) Modelling of maintenance strategy of offshore wind farms based multi-agent system. In: CIE44 \& ISSM14 (44th International Conference On Computers \& Industrial Engineering \& 9th International Symposiom On Intelligent Manufacturing And Service Systems), 591, pp 2406-2420

45. Santos P, Maudes J, Bustillo A (2015) Identifying maximum imbalance in datasets for fault diagnosis of gearboxes. Journal of Intelligent Manufacturing pp 119, DOI 10.1007/s10845-015-1110-0, URL http://dx.doi.org/10.1007/ s10845-015-1110-0 
46. Sheng S (2013) Report on wind turbine subsystem reliability-a survey of various databases. National Renewable Energy Laboratory, Golden, CO, Tech Rep NREL/PR5000-59111

47. Stenberg A, Holttinen H (2010) Analysing failure statistics of wind turbines in finland. In: European Wind Energy Conference, April, pp 20-23

48. Tavner $\mathrm{P}$ (2012) Offshore wind turbine reliability

49. Taylor JH, Sayda AF (2008) Prototype design of a multi-agent system for integrated control and asset management of petroleum production facilities. In: American Control Conference, 2008, IEEE, pp 4350-4357

50. Thornton EB, Guza R (1983) Transformation of wave height distribution. Journal of Geophysical Research: Oceans (1978-2012) 88(C10):5925-5938

51. Tian Z, Lin D, Wu B (2012) Condition based maintenance optimization considering multiple objectives. Journal of Intelligent Manufacturing 23(2):333-340

52. Tisue S, Wilensky U (2004) Netlogo: A simple environment for modeling complexity. In: International Conference on Complex Systems, pp 16-21

53. Trappey A, Trappey C, Ni WC (2013) A multi-agent collaborative maintenance platform applying game theory negotiation strategies. Journal of Intelligent Manufacturing 24(3):613-623, DOI 10.1007/s10845-011-0606-5, URL http://dx.doi. org/10.1007/s10845-011-0606-5

54. Zhang X, Wang W (2009) Wind farm and wake effect modeling for simulation of a studied power system. In: Power Systems Conference and Exposition, 2009. PSCE’09. IEEE/PES, IEEE, pp 1-6

55. Zhou W, Yang H, Fang Z (2006) Wind power potential and characteristic analysis of the pearl river delta region, china. Renewable Energy 31(6):739 - 753, DOI http://dx. doi.org/10.1016/j.renene.2005.05.006 